developing countries. Current donors include Australia, Bangladesh, Belgium, Canada, France, Japan, the Netherlands, Norway, Switzerland, the United Kingdom, and the United States; international organisations including the United Nations Children's Fund, United Nations Capital Development Fund, and the World Health Organisation; and private foundations including the Ford Foundation and Sasakawa Foundation.

We acknowledge the help of all the immunisation workers of the child health programme of the ICDDR,B, and the WHO expanded programme on immunisation, and the patients who gave us their time and cooperation. We also acknowledge the expanded programme on immunisation for the necessary logistics for immunisation. We are grateful to Mr M A Hasnat for his assistance with data analysis, Mr A R Patwary for invaluable help, and Dr Mridul K Chowdhury for his comments. We also express our sincere thanks to
Drs A K Mitra, R Bairagi, and K Stewart for reviewing the manuscript.

1 World Health Organisation. Expanded programme on immunization: progress and evaluation report. Geneva: WHO, 1989. (A42/10.)

2 Unicef. The state of the world's children. Oxford: Oxford University Press, 1991:102-3.

3 Greenland S, Robins JM. Estimation of a common effect parameter from sparse follow-up data. Biometrics 1985;41:55-68.

4 Schuler SR. Barriers to effective family planning in Nepal. Stud Fam Plann 1985;16:260-70.

5 Caldwell J. Routes to low mortality in poor countries. Population Developmen Review 1986;12:171-220.

6 Bairagi R. Is income the only constraint on child nutrition in rural Bangladesh? Bull World Health Organ 1988;58:767-72.

7 Gupta AD. Communicating immunization: a study of community attitudes and responses to immunization in Bangladesh. Dhaka: Worldwide International Foundation, 1988

Accepted 30 October 199

\title{
Physiotherapy intervention late after stroke and mobility
}

\author{
Derick T Wade, Fiona M Collen, Gillian F Robb, Charles P Warlow
}

\begin{abstract}
Objective-To determine whether the intervention of a physiotherapist improved mobility in patients seen more than one year after stroke.

Design-Randomised crossover trial comparing two groups offered intervention by a physiotherapist, one immediately after entry into the trial and the other after a delay of three months. The intervention consisted of identifying problems and offering advice and help to solve the problems.

Setting-Patients' homes in Oxfordshire.

Subjects-Patients who had reduced mobility due to a stroke more than one year before entry; 60 were recruited from a community stroke register and 34 in other ways.
\end{abstract}

Main outcome measures-Standard measures of mobility including gait speed, functional ambulation categories, the Nottingham extended activities of daily living index, and individual items from the Barthel activities of daily living index and the Frenchay activities index. Measures of manual dexterity, depression, and anxiety were used as controls.

Results -94 patients entered the trial and 49 were randomised to immediate and 45 to delayed physiotherapy; 89 were compared at the crossover point. At randomisation the two groups were comparable. At three months the group given early therapy showed an improvement in gait speed whereas the untreated group had declined (differences of $-3.9 v$ $6.4 \mathrm{~s}$ to walk $10 \mathrm{~m} ; \mathrm{p}<0.01$ ); between three and six months the group given delayed therapy showed improvement and the previously treated group declined (differences of $6.5 v-3.9 \mathrm{~s}$ to walk $10 \mathrm{~m}$; $\mathrm{p}<0.01)$. A $9 \%(95 \%$ confidence interval $0 \%$ to $18 \%)$ decrease in time taken to walk $10 \mathrm{~m}$ was associated with treatment and a $12 \%(2 \%$ to $19 \%)$ increase when patients were untreated. Other measures did not change significantly.

Conclusion-Intervention of an experienced physiotherapist late after stroke specifically improves mobility, albeit by a small amount, but the effects do not seem to be maintained, perhaps because there is an underlying decline in mobility in these patients. Gait speed offers a simple and sensitive measure of outcome.

\section{Introduction}

Over half of all stroke survivors have continuing problems with mobility, '2 although not all these prob- lems arise from the stroke. Many doctors and patients think that physiotherapy may help. Some studies suggest that late rehabilitation might lead to considerable general benefit ${ }^{3+}$ but there is little specific evidence to guide doctors, therapists, or managers when considering physiotherapy after stroke. Further, none of the few randomised studies on rehabilitation after stroke have specifically investigated the effect on mobility. Some small studies have investigated the effects on mobility of particular interventions such as the use of foot splints or biofeedback. ${ }^{56}$

The Oxfordshire community stroke project's register of long term stroke survivors ${ }^{7}$ allowed us to study the effects on mobility of physiotherapy given to patients who would not be expected to show much spontaneous change and yet for whom physiotherapy is often suggested. We investigated the effects on patients' mobility of being seen, advised, and sometimes treated by a physiotherapist late after stroke. The primary aim was to detect whether mobility improved as a result of the intervention. The design incorporated a control group given therapy after a delay, and a modified crossover analysis was also undertaken.

\section{Method}

All patients studied had mobility problems more than one year after stroke: they used a walking or mobility aid, other than just a stick; had had a fall in the previous three months; were unable to manage stairs, slopes, or uneven surfaces independently; or had a slow gait speed $>10 \mathrm{~s}$ over $10 \mathrm{~m}$ if under $60,>12 \cdot 5 \mathrm{~s}$ if $60-69,>16 \cdot 5 \mathrm{~s}$ if over $70 .^{2}$ Patients who had agreed to enter the trial were accepted unless we were unable to detect an impairment related to stroke that was likely to reduce mobility and also able to identify an alternative cause for impaired mobility.

Most patients $(n=60)$ were recruited from the 328 survivors in the Oxfordshire community stroke project. ${ }^{78}$ At final follow up two to seven years after their first stroke patients were assessed for mobility and, if eligible, they were asked to enter the study. Those accepting were contacted six to 12 months later and assessed by a non-treating physiotherapist who decided whether the mobility problems were due to stroke; if so the patient was entered into the trial.

Calculations based on published evidence ${ }^{129}$ sug gested that a sample of 100 patients would give an $80 \%$ chance at the $5 \%$ level of detecting a one category improvement - for example, in walking outdoors - in $10 \%$ of patients. We expected to recruit this number
Correspondence to:

B.MF 1992:304:609-13 


\begin{tabular}{|c|c|c|c|c|c|}
\hline \multirow[b]{2}{*}{ Time after entry } & \multicolumn{2}{|c|}{ Early treatment } & \multicolumn{3}{|c|}{ Late treatment } \\
\hline & No & Treatment & & No & Treatment \\
\hline \multicolumn{6}{|l|}{ Baseline assessments: } \\
\hline No seen at 0 weeks & \multirow{2}{*}{\multicolumn{2}{|c|}{$\begin{array}{l}49 \\
49\end{array}$}} & \multicolumn{3}{|c|}{45} \\
\hline No seen at $1-6$ weeks (mean (SD) $2 \cdot 2(0 \cdot 7)$ weeks, median 2 weeks) & & & \multirow{2}{*}{\multicolumn{2}{|c|}{45}} & \\
\hline Randomisation: & \multicolumn{2}{|r|}{ Start } & & & \\
\hline \multicolumn{6}{|l|}{ Follow up assessments: } \\
\hline No seen at first follow up (13-28 weeks; mean (SD) 17.4 (2.8) weeks, median 17 weeks): & 4 & Ended & \multirow[b]{2}{*}{2} & 41 & \multirow[t]{2}{*}{ Start } \\
\hline No died & 0 & & & & \\
\hline No refused & 1 & & 2 & & \multirow{3}{*}{ Ended } \\
\hline No seen at second follow up (27-44 weeks; mean (SD) $32 \cdot 1(3 \cdot 5)$ weeks, median 31 weeks) & \multicolumn{2}{|c|}{47} & \multirow{2}{*}{\multicolumn{2}{|c|}{39}} & \\
\hline $\begin{array}{l}\text { No died } \\
\text { No seen at third follow up ( } 34-77 \text { weeks; mean (SD) } 45 \text { (4.4 weeks, median } 44 \text { weeks): }\end{array}$ & \multirow{2}{*}{\multicolumn{2}{|c|}{40}} & 2 & & \\
\hline $\begin{array}{l}\text { No seen at thira lollow up ( } 34-1 / \text { weeks; mean (SD) } 4 J(4.4 \text { weeks, median } 44 \text { weeks): } \\
\text { No not seen (entered too late) }\end{array}$ & & & 4 & \multicolumn{2}{|c|}{35} \\
\hline No died & 1 & & 0 & & \\
\hline
\end{tabular}

TABLE II - Physiotherapy intervention in 89 patients

\begin{tabular}{|c|c|c|}
\hline Problem area & $\begin{array}{l}\text { No }(\%) \text { of } \\
\text { patients }\end{array}$ & Interventions \\
\hline Walking & $70(79)$ & \\
\hline Abnormal gait pattern & & Re-education of abnormal components \\
\hline $\begin{array}{l}\text { Unsafe walking outside } \\
\text { Standing balance }\end{array}$ & & Practice walking inside and outside \\
\hline Standing balance & $57(64)$ & \\
\hline Unable to stand alone & & Exercises to stimulate reactions \\
\hline Difficulty changing direction & & $\begin{array}{l}\text { Obstacle courses } \\
\text { Practice on uneven surfaces }\end{array}$ \\
\hline Sitting to standing & $50(56)$ & \\
\hline Difficulty rising from bath seat, toilet, low sofa & & $\begin{array}{l}\text { Re-education; practice of correct sequence (feet back, } \\
\text { lean forward) }\end{array}$ \\
\hline Equipment: & & \\
\hline Unused & $41(46)$ & Removal of inappropriate aids \\
\hline Unsafe & $40(45)$ & Maintenance, adjustment \\
\hline Lacking & $35(39)$ & Provision of appropriate aids \\
\hline Activities of daily living & $38(43)$ & \\
\hline $\begin{array}{l}\text { Difficulties with bathing, transfers, getting off } \\
\text { floor }\end{array}$ & & $\begin{array}{l}\text { Advice on and practice of best way of performing } \\
\text { activity; referral to community occupational } \\
\text { therapist }\end{array}$ \\
\hline Behaviour & $30(34)$ & Demonstrate natient's a hility to natient and carer \\
\hline $\begin{array}{l}\text { Lack of confidence; adoption of sick role } \\
\text { Exercise tolerance }\end{array}$ & $8(9)$ & lonstrate patient s ability to patient and carer \\
\hline Breathless on exertion; reduced fitness & & Graduated exercise programme \\
\hline
\end{tabular}

^All patients had more than one problem identified.

from the 328 Oxfordshire community stroke project survivors, but although 190 had mobility disability, 97 refused entry into the study; the mobility problems of 18 were not related to stroke; 11 died after recruitment but before entry; and four were lost, leaving 60 to be entered. ${ }^{8}$ Additional patients were recruited in various ways: contacting patients discharged from Rivermead Rehabilitation Centre more than six months earlier (12 patients); asking local general practitioners (six); an appeal over the radio (four); and contacting community workers $(10)$. Two patients referred themselves after hearing about the trial. After confirmation that the patients had suffered a stroke more than one year before entry, they were assessed in the same way as the other patients.

Once accepted into the trial, each patient was assessed by an independent (non-treating) physiotherapist immediately, one to six weeks later, and then about three, six, and nine months after the second assessment. Assessments took place at the patient's home, and the independent assessor was not informed of the patient's treatment group. Ten patients were entered too late to complete the last assessment.

Table I shows the trial design. There were two initial assessments, primarily to monitor the reliability of the assessment procedures. After the second assessment, patients were randomised to receive physiotherapy either immediately or after a three month delay (that is, after the assessment at three months). Thus at the assessment at three months half the patients had had the intervention and half were controls. Randomisation was by restricted randomisation (permuted blocks of 10 ) with random number tables. ${ }^{10}$

A range of standardised outcome assessments was used-some specifically measuring mobility, some including items on mobility, and some unrelated to mobility - to collect control information. A wide variety of measures was used because the patients had a wide range of disabilities, but assessment was not tiring and was usually complete within 40 minutes; most assessments required only questioning the patient or relative. The measures were the motricity index, ${ }^{11} 12$ the functional ambulation categories, ${ }^{13}$ the Rivermead motor assessment, ${ }^{11} 14$ the Barthel activities of daily living index,,$^{15}$ the Frenchay activities index ${ }^{16}$ gait speed measured over 10 metres indoors, which we have shown to be reliable, ${ }^{11}$ an early version of the Rivermead mobility index ${ }^{17}$ the Nottingham extended activities of daily living index,$^{18}$ the hospital anxiety and depression scale, ${ }^{19}$ and the nine hole peg test of manual dexterity. ${ }^{20}$ Data from the nine hole peg test were analysed as the number of seconds taken to place each peg. Validity and reliability have been established for most of these measures. ${ }^{11-20}$ Other information was collected clinically.

Four hypotheses were tested: firstly, that during treatment patients would show improvement in mobility which would not be observed when they were not being treated (specifically we expected to see an increase in gait speed); secondly, that this improvement would be sustained for six months after treatment ended; thirdly, that the effects would be restricted to mobility and would not affect manual dexterity; and, fourthly, that there would not be an increase in depression or anxiety caused by treatment.

Data were entered on to a microcomputer and analysed with the SPSS PC+ statistical package. Analyses were of direct comparison of the two groups

TABLE III-Characteristics of groups of patients at entry into study. Values are numbers (percentages) unless otherwise stated

\begin{tabular}{lcc}
\hline & $\begin{array}{c}\text { Early } \\
\text { intervention } \\
(\mathbf{n}=49)\end{array}$ & $\begin{array}{c}\text { Late } \\
\text { intervention } \\
(\mathbf{n}=45)\end{array}$ \\
\hline Mean (SD) age (years) & $72 \cdot 3(9 \cdot 7)$ & $72 \cdot 0(10 \cdot 6)$ \\
Men & $27(55)$ & $20(44)$ \\
Women & $22(45)$ & $25(66)$ \\
Arthritis in lower limb & $15(31)$ & $8(18)$ \\
Recent physiotherapy & $5(10)$ & $4(9)$ \\
Side of lesion: & $25(51)$ & $21(47)$ \\
$\quad$ Left hemisphere & $19(39)$ & $21(47)$ \\
Right hemisphere & $5(10)$ & $3(7)$ \\
$\quad$ Brain stem & $10 \cdot 0(3 \cdot 7)$ & $10 \cdot 0(3 \cdot 1)$ \\
Mean(SD) motricity index in affected leg & & \\
$\quad$ (0-15) & $26(53)$ & $18(40)$ \\
Sensory loss: & $22(45)$ & $26(58)$ \\
$\quad$ No & $1(2)$ & $1(2)$ \\
Yes & & \\
$\quad$ Not known & $43(88)$ & $40(89)$ \\
Communication (clinically judged): & $6(12)$ & $5(11)$ \\
$\quad$ Normal & & $40(89)$ \\
Abnormal & $44(90)$ & $40(11)$ \\
Cognition (clinically judged): & $5(10)$ & $5(11)$ \\
$\quad$ Normal & & $1(2)$ \\
Abnormal & $1(2)$ & $4(9)$ \\
Functional ambulation categories: & $7(14)$ & $28(62)$ \\
$\quad 0$ & $30(61)$ & $12(27)$ \\
1-3 & $11(22)$ & $9(20)$ \\
4 & $13(27)$ & $32(71)$ \\
5 & $33(67)$ & $4(9)$ \\
Type of care: & $3(6)$ & $59 \cdot 6(35 \cdot 3)$ \\
$\quad$ Civing alone & & \\
$\quad$ Institution & $53 \cdot 1(29 \cdot 5)$ & \\
Mean (SD) delay in treatment for stroke & & \\
(months) & & \\
\hline & &
\end{tabular}


at the two preliminary assessments and at each follow up point; of change in scores between pairs of consecutive assessments in the two groups; and of change in scores between the six month and nine month assessments in those followed up that long. Lastly, the change occurring during the treatment phase was compared with the change during non-treatment, much as in a crossover trial. ${ }^{2}$

All patients were included in all analyses unless they had died or had not reached the last follow up point when the study ended. For measures of gait speed and manual dexterity a varying number of patients were able to perform the test (for example, some patients had stopped or started walking), and so the number analysed was different at each point, as shown in the relevant tables.

TABLE IV - Scores at main assessment points. Values are means $(S D)$ unless otherwise stated

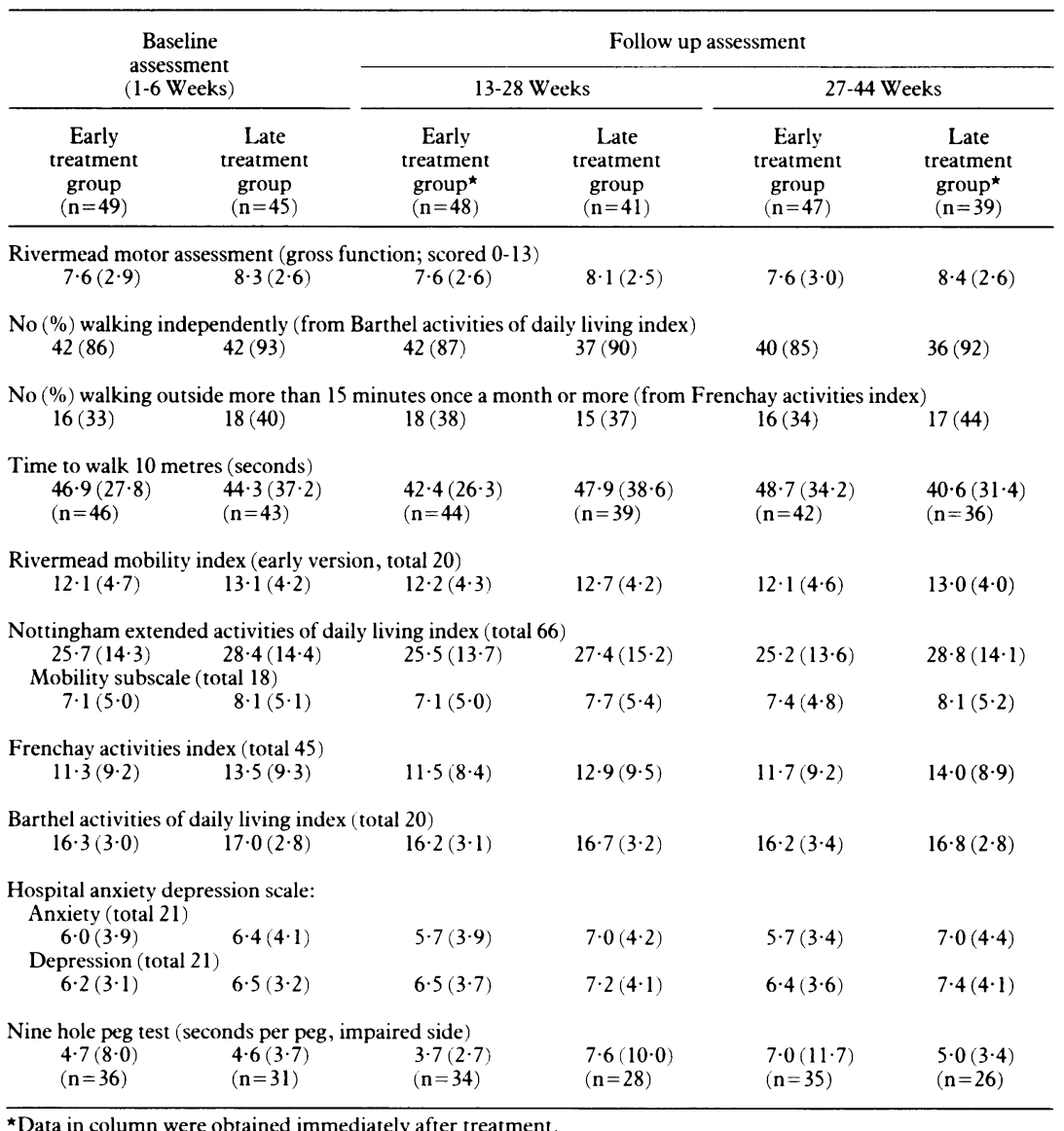

*Data in column were obtained immediately after treatment.
The tests of statistical significance used were unpaired $t$ and paired $t$ tests and $\chi^{2}$ analysis. ${ }^{10}$ Significance was at the $5 \%$ level for the planned comparisons of gait speed and numbers walking, and at the $1 \%$ level for other variables because of the large number of comparisons being made.

Intervention by a physiotherapist (FC) experienced in neurological rehabilitation was given to the 89 patients seen (two died before their treatment started and three refused treatment). A problem solving approach was used, and table II shows the main problems identified and interventions undertaken. Patients were assessed, with particular reference to mobility, and problem areas were identified. Realistic, achievable goals were discussed with the patient and carers and then the physiotherapist intervened if required. The most common intervention was to offer advice to patients and carers - for example, on how problems could be overcome. The emphasis at this late stage after stroke was on self management.

All visits and treatments were carried out in the patients' homes throughout Oxfordshire. Seven patients lived in residential care. The number of visits varied (mean (SD) $4(2 \cdot 5)$, range 1-11); most patients $(65 ; 73 \%)$ were seen one to six times. The total time for the initial visit (including travel and administration) ranged from 1 hour 10 minutes to 3 hours 10 minutes (mean (SD) 2 hours 4 minutes (28 minutes); median 2 hours 5 minutes).

\section{Results}

Ninety four patients were randomised. Patients from the Oxfordshire community stroke project were less disabled than those recruited in other ways. However, the groups given immediate therapy and delayed therapy were similar in most respects at the time of randomisation, and no significant differences were found in the variables shown in tables III and IV or in any environmental factor measured, such as distance from the road or steps within the house.

Table IV shows the results at the three assessment points. At the first follow up assessment the treated (trial) group was compared with the untreated (control) group; the average time to walk $10 \mathrm{~m}$ was 4.5 seconds less in the treated group but had increased by 3.6 seconds in the untreated group. At the second follow up the group that had just been given therapy took less time to walk $10 \mathrm{~m}$ and the group given early therapy (who had received no therapy since the previous assessment) took longer. However, all measures varied considerably and none of the differ-

TABLE V-Change between assessment

\begin{tabular}{|c|c|c|c|c|c|c|c|c|}
\hline & \multicolumn{2}{|c|}{$\begin{array}{c}\text { First to second baseline } \\
\text { assessment }\end{array}$} & \multicolumn{2}{|c|}{$\begin{array}{l}\text { Second baseline to first } \\
\text { follow up assessment }\end{array}$} & \multicolumn{2}{|c|}{$\begin{array}{l}\text { First to second } \\
\text { follow up assessment }\end{array}$} & \multicolumn{2}{|c|}{$\begin{array}{l}\text { Second to third } \\
\text { follow up assessment }\end{array}$} \\
\hline & $\begin{array}{l}\text { Early } \\
\text { treatment } \\
\text { group } \\
(\mathrm{n}=49)\end{array}$ & $\begin{array}{l}\text { Late } \\
\text { treatment } \\
\text { group } \\
(\mathrm{n}=45)\end{array}$ & $\begin{array}{c}\text { Early } \\
\text { treatment } \\
\text { group } \\
(\mathbf{n}=48)\end{array}$ & $\begin{array}{l}\text { Late } \\
\text { treatment } \\
\text { group } \\
(n=41)\end{array}$ & $\begin{array}{c}\text { Early } \\
\text { treatment } \\
\text { group } \\
(\mathrm{n}=47)\end{array}$ & $\begin{array}{c}\text { Late } \\
\text { treatment } \\
\text { group } \\
(\mathbf{n}=39)\end{array}$ & $\begin{array}{l}\text { Early } \\
\text { treatment } \\
\text { group } \\
(\mathrm{n}=40)\end{array}$ & $\begin{array}{c}\text { Late } \\
\text { treatment } \\
\text { group } \\
(\mathbf{n}=35)\end{array}$ \\
\hline \multicolumn{9}{|c|}{ Walking independently (from Barthel activities of daily living index): } \\
\hline No stopped & 0 & 1 & $1 \cdot$ & 1 & 2 & 1 & 0 & 0 \\
\hline No started & 0 & 0 & 1 & 0 & 0 & 1 & 0 & 0 \\
\hline \multicolumn{9}{|c|}{ Walking outdoors at least once a month (from Frenchay activities index): } \\
\hline No stopped & 3 & 2 & 2 & 2 & 3 & 1 & 5 & 5 \\
\hline \multirow{2}{*}{\multicolumn{9}{|c|}{ Mean (SD) change in time to walk $10 \mathrm{~m}$ (seconds): $\ddagger$}} \\
\hline & & & & & & & & \\
\hline & $\begin{array}{c}-0 \cdot 5(16 \cdot 6) \\
(n=45)\end{array}$ & $\begin{array}{c}-1 \cdot 8(13 \cdot 7) \\
(n=43)\end{array}$ & $\begin{array}{c}-3 \cdot 9(20 \cdot 3) \\
(n=44)\end{array}$ & $\begin{array}{l}6 \cdot 4(21 \cdot 5) \dagger \\
(\mathrm{n}=39)\end{array}$ & $\begin{array}{l}6 \cdot 5(17 \cdot 7) \\
(n=42)\end{array}$ & $\begin{array}{l}-3.9(15.7) \dagger \\
(\mathbf{n}=35)\end{array}$ & $\begin{array}{c}-1 \cdot 4(13 \cdot 9) \\
(n=35)\end{array}$ & $\begin{array}{l}2 \cdot 6(9 \cdot 7) \\
(\mathrm{n}=34)\end{array}$ \\
\hline \multicolumn{9}{|c|}{ Mean (SD) change in mobility score on Nottingham extended activities of daily living index (total 21) } \\
\hline & $0 \cdot 1(3 \cdot 4)$ & $0 \cdot 04(2 \cdot 2)$ & $-0 \cdot 21(3 \cdot 4)$ & $-0 \cdot 12(2 \cdot 3)$ & $0 \cdot 23(2 \cdot 9)$ & $-0.05(2 \cdot 9)$ & $-0 \cdot 10(2 \cdot 0)$ & $0 \cdot 40(2 \cdot 2)$ \\
\hline \multicolumn{9}{|c|}{ Mean (SD) change on nine hole peg test (seconds per peg, impaired side) $\ddagger$} \\
\hline & $\begin{array}{c}-0 \cdot 2(0 \cdot 9) \\
(\mathbf{n}=33)\end{array}$ & $\begin{array}{c}-1 \cdot 7(6 \cdot 2) \\
(n=30)\end{array}$ & $\begin{array}{l}0 \cdot 27(1 \cdot 7) \\
(\mathrm{n}=34)\end{array}$ & $\begin{array}{l}1 \cdot 16(3 \cdot 5) \\
(n=27)\end{array}$ & $\begin{array}{l}0 \cdot 68(2 \cdot 7) \\
(\mathrm{n}=33)\end{array}$ & $\begin{array}{l}-1 \cdot 07(3 \cdot 3) \\
(\mathrm{n}=26)\end{array}$ & $\begin{array}{l}-0 \cdot 30(1 \cdot 9) \\
(\mathbf{n}=30)\end{array}$ & $\begin{array}{l}0 \cdot 83(2 \cdot 9) \\
(\mathrm{n}=25)\end{array}$ \\
\hline \multicolumn{9}{|c|}{$\begin{array}{l}\text { Hospital Anxiety and Depression Scale: } \\
\text { Mean (SD) change in anxiety score }\end{array}$} \\
\hline \multicolumn{9}{|c|}{$\begin{array}{l}\text { Not done } \\
\text { Mean (SD) change in depression score }\end{array}$} \\
\hline & Not done & Not done & $0.4(2 \cdot 9)$ & $0.4(3 \cdot 8)$ & $0 \cdot 1(2 \cdot 6)$ & $0 \cdot 3(3 \cdot 0)$ & $0 \cdot 2(2 \cdot 2)$ & $-0 \cdot 3(2 \cdot 7)$ \\
\hline
\end{tabular}

^Treatment period. $\quad \nmid p<0 \cdot 01 . \quad \ddagger$ Some patients could not undertake this test on one or more occasions. 
ences between groups were statistically significant.

The changes between assessments in individual patients are shown in table V. Two measures changed in association with treatment. In each group the average time taken to walk $10 \mathrm{~m}$ was reduced by 3.9 seconds at the assessment immediately after treatment while the untreated group took about 6.5 seconds longer at the end of the non-treatment phase; the difference in change between the two groups was significant $(t=2 \cdot 71, \mathrm{p}<0 \cdot 01)$. Secondly, during treatment seven patients started walking outside and three stopped, while during the period of no treatment two started and five stopped $\left(\chi^{2}=2 \cdot 0, p>0 \cdot 05\right)$. Ten patients stopped walking outdoors over the last three months of the study, when they were no longer receiving therapy.

There were no significant differences in the change (or absolute values) in performance on the nine hole peg test, confirming that the treatment effect was specific to mobility. There was considerable fluctuation, which arose primarily because a few individuals placed a single peg on one occasion (thus entering the analysis) and failed absolutely on other occasions (thus being excluded from analysis). There was no significant change in anxiety or depression (hospital anxiety and depression scale scores), and there were no other changes associated with treatment.

The third analytical approach was to compare the change occurring in all patients during their treatment period with the change that arose in the untreated period. During treatment the time taken to walk $10 \mathrm{~m}$ was reduced by 4.2 seconds ( $95 \%$ confidence interval 0 to 8.4 seconds) and in the no treatment period the time taken to walk $10 \mathrm{~m}$ increased by $4.9(1 \cdot 1$ to $8 \cdot 7)$ seconds. Analysis of variance ${ }^{1021}$ showed a definite treatment effect $(t=2 \cdot 5, \mathrm{p}<0.05)$ but no period effect $(t=0.9, \mathrm{p}>0.05)$ : the deterioration seen when not receiving treatment was similar whether treatment had been given previously or not. The deterioration seen in the group not receiving treatment suggests an underlying decline in mobility, which was temporarily reversed by treatment for a maximum of three months.

\section{Discussion}

This study shows that the intervention of an experienced physiotherapist can improve mobility and reduce disability in patients seen late after a stroke. The results also suggest that elderly patients may have a continuing decline in mobility after a stroke and do not necessarily have a stable disability. The patients studied were representative of most long term survivors of stroke, and the measures used concentrated on disability.

\section{STUDY DESIGN}

The best design in treatment evaluation-the randomised, double blind trial-is difficult to use in rehabilitation research. The design we used was practical and overcame most (but not all) objections. The success of the randomisation can be seen in the close comparability of the two groups, but as there was no direct placebo treatment the patients were not blind to the intervention.

Most analyses used are standard, but we also undertook an analysis of variance on the change in time taken to walk $10 \mathrm{~m}$. This analysis is common in drug treatment crossover trials. ${ }^{21}$ Assuming that change in disability will occur soon after the treatment phase, then this analysis seems valid. The fact that no period effect was detected confirms that the effect of therapy was only temporary.

There were three types of control. Firstly, the effects of being assessed in a study applied equally to both groups. Secondly, there was an untreated group, most obvious at the first three month follow up but also at the six month follow up, when the group treated initially had been three months without treatment. This control should take account of any spontaneous improvement, which in any event is considered unlikely so late after stroke. Indeed our study suggests that, if anything, deterioration was occurring. Lastly, there were controls for any non-specific effects on morale, the most obvious being measures of manual dexterity and measures of mood; no significant changes were seen in these untargeted measures.

The main possible source of bias was the observer, but we made great efforts to ensure that she was unbiased: she was never involved in treatment; she was never told which group the patient was in; she was never given any information about the patient other than name, address, and minimal information on the stroke (such as, how long ago); and she never had the results of preceding assessments with her. Of course, patients and relatives often mentioned whether or not the treating therapist had visited, but after the first three months of the study this gave little clue about which group the patient was in. We concluded that systematic observer bias was unlikely.

Various alternative designs were considered and rejected. The most persuasive was to set a goal for each patient at entry, and then to see whether treatment was associated with achieving the goal. We thought that the process of assessing patients in detail and discussing goals with them was likely to be an important part of any intervention. For example, the mere suggestion that going upstairs was possible might lead patients to try and to succeed, overcoming their previous disability.

Another complicating factor affecting any study on stroke is the effect of intercurrent illness, death, and other events such as bereavement, all likely in this population. All living patients were included in every analysis. Assessments were occasionally delayed one week if someone had been discharged from hospital within the past few days, but assessments otherwise took place on time regardless of external events.

Lastly, in regard to design, the study included fewer patients than we hoped, which may explain why we failed to detect a significant increase in the numbers of patients walking outside. Our power calculations showed that we needed at least 100 patients to detect a $10 \%$ increase in the number of patients walking outside. This shortfall occurred despite prolonging the recruitment period by six months and making considerable efforts to recruit patients.

\section{OUTCOME MEASURES}

The appropriateness and sensitivity of measures gave rise to considerable concern, especially to the therapists consulted, who felt that the measures would not detect useful benefits achieved, particularly in quality of walking. The measures chosen had to focus on disability, had to be easily used in the home, and had to be applicable to a wide range of patients with a wide range of disabilities. Tailoring an assessment to each patient's problems was considered, but this design had the problems discussed earlier. Consequently a range of measures was used, covering the areas most likely to show improvement of clinical importance.

Gait speed was chosen as the primary outcome measure. It is undoubtedly a valid measure of mobility: it correlates closely with any aids being used, ${ }^{2}$ and it relates to the frequency of fall ${ }^{22}$ and to other measures. ${ }^{1322-24}$ Its reliability is known. ${ }^{211}$ It is simple, being easily measured in patients' homes. ${ }^{.1}$ It is a ratio measure, sensitive to change. In fact it was the only outcome measure to show improvement, confirming a 
recent study that found gait speed was more sensitive to change than was a categorical measure..$^{25}$

We observed an $8 \%$ improvement in gait speed in association with treatment, and statistical analysis suggests this was probably not due to chance. At the same time the $8 \%$ increase in the number of patients walking outside did not reach significance. There is no way to judge the clinical importance of the improved gait speed itself, particularly in the absence of any significant change in other measures such as the number of patients walking outside. We believe from the evidence given above and elsewhere ${ }^{26}$ that any improvement in gait speed reflects a genuine improvement in mobility even if our categorical measures failed to detect it, because gait speed is a more sensitive and yet equally valid measure.

This study also suggests that after stroke there is a general decline in mobility with time. Our analysis showed a $12 \%$ deterioration in gait speed in the untreated group, and statistical analysis suggests that this was not simply due to chance. It is notable that 10 of 75 patients followed up for nine months stopped walking outdoors in the last three months of follow up. Possibly treatment arrested or reversed the decline in mobility.

The measures used also may not capture all improvements seen clinically, because the variation between patients is so great that no limited group of measures is likely to achieve this. For example, a reduction in the amount of personal support needed would not necessarily have been detected, nor would an improvement from using a delta rollator to using a stick, but both are likely to be associated with an improved gait speed.

\section{INTERVENTION}

The greatest difficulty in rehabilitation research is to define accurately the intervention being studied. This has been done in outline in the methods section. It is important to emphasise that although many of the actions seem simple (for example, giving advice on appropriate levels of activity), this advice can only be given by (and will only be accepted from) someone with considerable experience. The advice depends on an adequate initial assessment, which in turn requires an experienced physiotherapist.

The mechanism underlying the observed effects is unknown, but presumably intervention has not fundamentally reduced underlying impairments such as weakness. Whatever the mechanism, the improvement was not maintained, suggesting that follow up visits could maintain (and possibly increase) function.

The service implications of our research are unclear. There seems little doubt that intervention had a definite beneficial effect on mobility in some patients, but it is difficult to assess the clinical importance of the change or to calculate comparative cost effectiveness. The results suggest, however, that domiciliary treatment can be of benefit. The benefit depends on seeing an experienced therapist, but the amount of intervention needed may be relatively small.

\section{CONCLUSIONS}

What conclusions can be drawn? Firstly, research into rehabilitation using a randomised trial design with objective outcome measures is possible; we used a crossover design with repeated measures. Next, outcome can be measured with simple clinical instruments, and gait speed is an extremely good outcome measure in that it is sensitive to change. Walking outside is probably the second most sensitive measure, but more patients would be needed in any future trial to show an increase in the number of patients walking outside.
Moreover, short term changes may reflect the effects of weather as much as of therapy. Thirdly, it seems likely that, after a period of recovery, patients who have survived a stroke experience a continuing decline in mobility. Finally, we conclude that it may be worth while for an experienced physiotherapist to assess and treat patients with problems of mobility due to stroke even long after the stroke. The intervention can improve mobility, although how and by how much is not yet known.

The study was funded by the Medical Research Council. We acknowledge the continued cooperation of the participating general practitioners and their patients. Mrs Val Berry undertook all administration admirably; Dr John Burn saw al patients at final follow up of the Oxfordshire community stroke project and enrolled them. Additional help and advice was given by John Bamford, Carol Bradshaw, Janet Cross, Martin Dennis, Leslie Jones, Vanessa Langsbury, Peter Sandercock, Jim Slattery, Anne Wood, and all therapists in the Rivermead physiotherapy department.

1 Chin PL, Rosie A, Irving M, Smith R. Studies in hemiplegic gait. In: Rose FC, ed. Advances in stroke therapy. New York: Raven, 1982:197-211.

2 Wade D, Wood V, Heller A, Maggs J, Langton-Hewer R. Walking after stroke: measurement and recovery over the first three months. Scand Rehabil Med 1987;9:25-30.

3 Lehmann JF, DeLateur BJ, Fowler RS, Warren CG, Arnhold R, Schertzer G et al. Stroke: does rehabilitation affect outcome? Arch Phys Med Rehab 1975;56:375-82.

4 Smith DS, Goldenberg E, Ashburn A, Kinsella G, Sheikh K, Brennan PJ et al. Remedial therapy after stroke: a randomised controlled trial. $B M$ $1981 ; 282: 517-20$

5 Corcoran PJ, Jebson RH, Brengelman GL, Simons BC. Effects of plastic and metal leg braces on speed and energy cost of hemiparetic ambulation. Arch Phys Med Rehabil 1970;51:69-77.

6 Burnside IG, Tobias HS, Bursill D. Electromyographic feedback in the remobilisation of stroke patients: a controlled trial. Arch Phys Med Rehabil remobilisation of

7 Bamford J, Sandercock P, Dennis M, Warlow C, Jones L, McPherson K, et al. A prospective study of acute cerebrovascular disease in the community: the Oxfordshire community stroke project 1981-1986. 1: Methodology, demography and incident cases of first ever stroke. $\mathcal{F}$ Neurol Neurosurg Psychiatry 1988;51:1373-80.

8 Collen FM, Wade DT. Residual mobility problems after stroke. International Disability Studies 1991;13:12-5.

9 Wade DT, Langton-Hewer R. Functional abilities after stroke: measurement, natural history and prognosis. I Neurol Neurosurg Psychiatry 1987;50: $177-82$.

10 Armitage P, Berry G. Statistical methods in medical research. Oxford: Blackwell Scientific, 1987.

11 Collen FM, Wade DT, Bradshaw CM. Mobility after stroke: reliability of measures of impairment and disability. International Disability Studies 1990;12:6-9.

12 Collin C, Wade DT. Assessing motor impairment after stroke: a pilot reliability study. I Neurol Neurosurg Psychiatry 1990;53:567-9.

13 Holden MK, Gill KM, Magliozzi MR, Nathan J, Piehl-Baker L. Clinical gai assessment in the neurologically impaired: reliability and meaningfulness. Phys Ther 1984;64:35-40.

14 Lincoln N, Leadbitter D. Assessment of motor function in stroke patients. Physiotherapy 1979;65:48-51.

15 Collin C, Wade DT, Davis S, Horne V. The Barthel ADL index: a reliability study. International Disability Studies 1988;10:61-3.

16 Wade DT, Legh-Smith J, Langton-Hewer R. Social activities after stroke: measurement and natural history using the Frenchay activities index. International Rehabilitation Medicine 1985; 7:176-81

17 Collen FM, Wade DT, Robb GF, Bradshaw CM. The Rivermead mobility index, a further development of the Rivermead motor assessment. International Disability Studies 1991;13:50-4.

18 Nouri FM, Lincoln NB. An extended activities of daily living scale for strok patients. Clinical Rehabilitation 1987;1:301-5.

19 Zigmond AS, Snaith RP. The hospital anxiety and depression scale. Acta Psychiatr Scand 1983;67:361-70.

20 Heller A, Wade DT, Wood VA, Sunderland A, Langton-Hewer R, Ward E. Arm function after stroke: measurement and recovery over the first three Arm function after stroke: measurement and recove

21 Pocock SJ. Clinical trials: a practical approach. Chichester: Wiley, 1983 110-22.

22 Wolfson L, Whipple R, Amerman P, Tobin JN. Gait assessment in the elderly a gait abnormality rating scale and its relation to falls. $f$ Geront 1990;45: M12-9.

23 May D, Nayan USL, Isaacs B. The life-space diary: a measure of mobility in old people at home. Int Rehabil Med 1985;7:182-7.

24 Bradstater ME, de Bruin H, Gowland C, Clarke BM. Hemiplegic gait: analysis of temporal variables. Arch Phys Med Rehabil 1983;64:583-7.

25 Stewart DA, Burns JMA, Dunn SG, Roberts MA. The two-minute walking test: a sensitive index of mobility in the rehabilitation of elderly patients. Clin Rehabil 1990;4:273-6.

26 Wade DT. Measurement in neurological rehabilitation. Oxford: Oxford University Press, 1992:78-9. 